\title{
Desafios ao Bacharelado em Administração Pública do Instituto Federal da Paraíba para a melhoria do processo avaliativo no contexto do SINAES
}

Challenges to the Bachelor's Course in Public Administration of the Federal Institute of Paraiba for the improvement of the evaluation process in the context of the SINAES

\section{Retos de Grado en Administración Pública del Instituto Federal de Paraíba para mejorar el proceso de evaluación en el contexto del SINAES}

Marcos Vasconcelos Paiva ${ }^{1}$

Maria das Graças Gonçalves Vieira Guerra ${ }^{1}$

DOI: http://dx.doi.org/10.20435/serie-estudos.v26i57.1515

\begin{abstract}
Resumo: O objetivo da pesquisa é identificar os novos desafios à gestão do Bacharelado em Administração Pública (BAP), na modalidade de Educação a Distância (EaD) ofertado pelo Instituto Federal da Paraíba (IFPB), João Pessoa, diante da atualização do instrumento de avaliação de cursos de graduação (IACG) no ano de 2017, com foco no instrumento utilizado para a renovação e o reconhecimento de curso. A investigação consiste em um estudo de caso, de natureza aplicada, abordagem qualitativa e objetivo descritiva, com a coleta de dados realizada por procedimento documental. Foram analisados cinco indicadores de desempenho de conceito 3, menor valor obtido no último relatório de avaliação externa in loco do curso, identificados como: material didático institucional; gabinetes de trabalho para professores em Tempo Integral; espaço de trabalho para coordenação do curso e serviços acadêmicos; sala de professores; e salas de aula. Destacaramse, ainda em análise, quatro indicadores incluídos no novo IACG, com aplicações comprovadas ao BAP: conhecimentos, habilidades e atitudes necessárias às atividades de tutoria; Ambiente Virtual de Aprendizagem (AVA); equipe multidisciplinar; e experiência no exercício da docência na EaD. Propõe-se, com a apresentação dos resultados, evidenciar os aspectos de insuficiência e os novos indicadores relacionados ao BAP que auxiliem os gestores nas tomadas de decisões diante das novas demandas do IACG, objetivando a melhoria da qualidade do processo avaliativo.
\end{abstract}

Palavras-chave: SINAES; BAP; IFPB; curso de graduação.

${ }^{1}$ Universidade Federal da Paraíba (UFPB), João Pessoa, Paraíba, Brasil. 


\begin{abstract}
The objective of the research is to identify new challenges for the management of the Bachelor's Degree in Public Administration (BAP), in the form of Distance Education (EaD) offered by the Federal Institute of Paraíba (IFPB), João Pessoa, in view of updating the instrument for the evaluation of undergraduate courses (IACG) in the year 2017, focusing on the instrument used for course renewal and recognition. The investigation consists of a case study, of an applied nature, qualitative approach and descriptive objective, with data collection performed by documentary procedure. Five concept 3 performance indicators were analyzed, the lowest value obtained in the last external evaluation report on site of the course, identified as: institutional teaching material; full-time teacher's offices; workspace for course coordination and academic services; teacher's room; and classrooms. Four indicators included in the new IACG, with proven applications to the BAP, were highlighted, still under analysis: knowledge, skills, and attitudes needed for tutoring activities; Virtual Learning Environment (VLA); multidisciplinary team; and experience in teaching at EaD. The presentation of the results proposes highlighting the insufficiency aspects and the new indicators related to the BAP, which will help managers make decisions in response to the new demands of the IACG, aiming at improving the quality of the evaluation process.
\end{abstract}

Keywords: SINAES; BAP; IFPB; undergraduate course.

Resumen: El objetivo de la investigación es identificar los nuevos desafíos para la gestión del Grado en Administración Pública (BAP), en la modalidad de Educación a Distancia (EaD) ofrecida por el Instituto Federal de Paraíba (IFPB), João Pessoa, con vistas a la actualización del instrumento de evaluación de cursos de pregrado (IACG) en el año 2017, centrándose en el instrumento utilizado para la renovación y el reconocimiento de los cursos. La investigación consiste en un estudio de casos, de naturaleza aplicada, enfoque cualitativo y objetivo descriptivo, con la recopilación de datos realizada por procedimiento documental. Se analizaron cinco indicadores de rendimiento del concepto 3, el valor más bajo obtenido en el último informe de evaluación externa in situ del curso, identificados como: material didáctico institucional; oficinas del profesorado a tiempo completo; espacio de trabajo para la coordinación del curso y los servicios académicos; sala del profesorado; y aulas. Se destacaron cuatro indicadores incluidos en el nuevo IACG, con aplicaciones probadas al BAP, que aún están en proceso de análisis: conocimientos, aptitudes y actitudes necesarios para las actividades de tutoría; entorno de Aprendizaje Virtual (EVA); equipo multidisciplinario; y experiencia en la enseñanza en la EaD. La presentación de los resultados tiene por objeto poner de relieve los aspectos de insuficiencia y los nuevos indicadores relacionados con el PAB que ayudan a los administradores a tomar decisiones frente a las nuevas exigencias del IACG, con el fin de mejorar la calidad del proceso de evaluación.

Palabras clave: SINAES; BAP; IFPB; curso de graduación.

\title{
1 INTRODUÇÃO
}

Em análise às políticas públicas nacionais voltadas para a educação, notase uma evidente valorização sobre a avaliação da qualidade das Instituições de Ensino Superior (IES) e dos cursos de graduação. Essa atenção deriva de debates sobre o tema, que vão desde o ponto de vista da educação como direito básico para a formação humana, até uma visão estritamente mercadológica. 
No Brasil, a precaução com a avaliação da qualidade da Educação Superior perpassa, historicamente, diversos marcos legais - entre Diretrizes e Bases da Educação Nacional, Planos Nacionais de Educação e a própria Constituição Federal -, além de estudos acadêmicos e discussões nas esferas de planejamento e gestão organizacional de entidades públicas e privadas, tornando-se um referencial para a definição de objetivos e metas.

Um dos destaques referentes às políticas públicas está a criação, no ano de 2004, do- Sistema Nacional de Avaliação da Educação Superior (SINAES). O SINAES regulariza medidas avaliativas que subsidiam, por meio dos seus resultados, atos autorizativos de credenciamento, recredenciamento e transformação de organização acadêmica das IES públicas e privadas; e de autorização, reconhecimento e renovação de reconhecimento dos seus cursos de graduação.

Como uma de suas principais finalidades, a avaliação proposta pelo SINAES objetiva a melhoria da qualidade da Educação Superior brasileira, construindo um panorama qualificativo das instituições e dos cursos ofertados, por meio da realização de análises contínuas definidas em ciclos avaliativos trienais.

Entre as IES que integram essa análise, está o Instituto Federal da Paraíba (IFPB). A partir de 2008, a instituição hoje representada pelo IFPB foi inserida em um processo de mudança estrutural e político-pedagógica diante das novas atribuições como IES, apresentando uma evidente ampliação no quantitativo e nas modalidades de cursos de graduação, entre as quais, Bacharelado, Licenciatura e Tecnologia. Essa oferta expandiu-se tanto na modalidade presencial de ensino como na forma da Educação a Distância, a EaD.

Entre os cursos EaD, criados e ofertados pelo IFPB, está o Bacharelado em Administração Pública (BAP). O curso é ofertado pelo Campus João Pessoa desde o ano de 2013 e está inserido no âmbito do Sistema Universidade Aberta do Brasil (UAB), por intermédio do Programa Nacional de Formação em Administração Pública, o PNAP.

O curso obteve, ao final do ano de 2012, a autorização para sua criação, e, por meio de avaliação realizada no ano de 2017, o seu reconhecimento. De acordo com a política de ciclos avaliativos trienais, determinada pelo SINAES, esse procedimento deve ocorrer novamente a partir do ano de 2020, quando o curso planeja obter a sua primeira renovação de reconhecimento. 
Por algumas características peculiares, os desafios do BAP, diante deste cenário de avaliação da qualidade da educação, tornam-se ainda mais complexos. Como um curso de modalidade EaD - com formatos, características e linguagens distintas do ensino presencial - inserido em uma instituição que se molda às atribuições da Educação Superior, considerando variáveis como pesquisa e extensão, traz à tona a necessidade de refletir sobre os desafios de gestão do BAP voltados aos processos avaliativos.

A metodologia que orientou este artigo foi, essencialmente, um estudo de caso, de natureza aplicada, de abordagem qualitativa e objetivo descritiva, com a coleta de dados realizada por procedimento documental. A coleta e a análise dos dados obtidos com a pesquisa - por meio de legislações e documentos oficiais, incluindo a consulta ao último relatório de avaliação do BAP - objetivam apresentar uma perspectiva complementar de apoio diante dos desafios da atualização do instrumento avaliativo que subsidiará a renovação de reconhecimento do curso.

\section{SINAES}

Como destaque para esta pesquisa, a Lei n. 10.861, de 14 de abril de 2004, foi responsável por instituir o SINAES. Esta política pública tem como objetivo principal conceber um sistema nacional de avaliação das IES públicas e privadas, dos cursos de graduação e do desempenho dos estudantes, utilizando-se de instrumentos avaliativos que subsidiem os processos de regulação e supervisão institucional e de cursos (BRASIL, 2004). De modo a aprofundar o conhecimento sobre o SINAES, torna-se necessário analisar as características que o definem, entre as quais, as finalidades, os princípios, a organização e o fluxo do sistema.

Nota-se que a busca da qualidade na Educação Superior se destaca como elemento-chave dentro das finalidades de criação do sistema. São ressaltados os benefícios resultantes dos processos de avaliação das IES e cursos, como a adequação da oferta de vagas, o melhor gerenciamento dos custos operacionais, o aumento da produtividade e dos resultados institucionais e acadêmicos. Enfatizase, ao final, a importância da avaliação como estímulo à atuação das instituições sobre a perspectiva social, com base em dimensões e princípios definidos. Para as autoras Cavalcanti e Guerra (2019, p. 10), em um ponto de vista objetivo à qualidade, podemos considerar que "O SINAES se traduz como uma das políticas do Estado brasileiro de avaliar a qualidade das IES, visando à melhoria da qualidade 
do ensino ofertado e buscando estratégias em ações futuras a serem tomadas por tais instituições".

Os princípios associados aos SINAES fornecem diretrizes necessárias para a organização e o fluxo dos processos integrados a esse sistema, bem como serve de base para a elaboração dos distintos instrumentos avaliativos. Entre os princípios, encontram-se a responsabilidade social, prática social com objetivos educativos, globalidade, legitimidade e regulação e controle.

Sob a perspectiva da organização, o sistema aborda, como eixos de análise das IES, os cursos de graduação e o desempenho dos estudantes. E, para cada um destes eixos, há processos, dinâmicas e instrumentos avaliativos específicos que se correspondem, como disposto, de forma simplificada, na Figura 1:

Figura 1 - Organização do SINAES

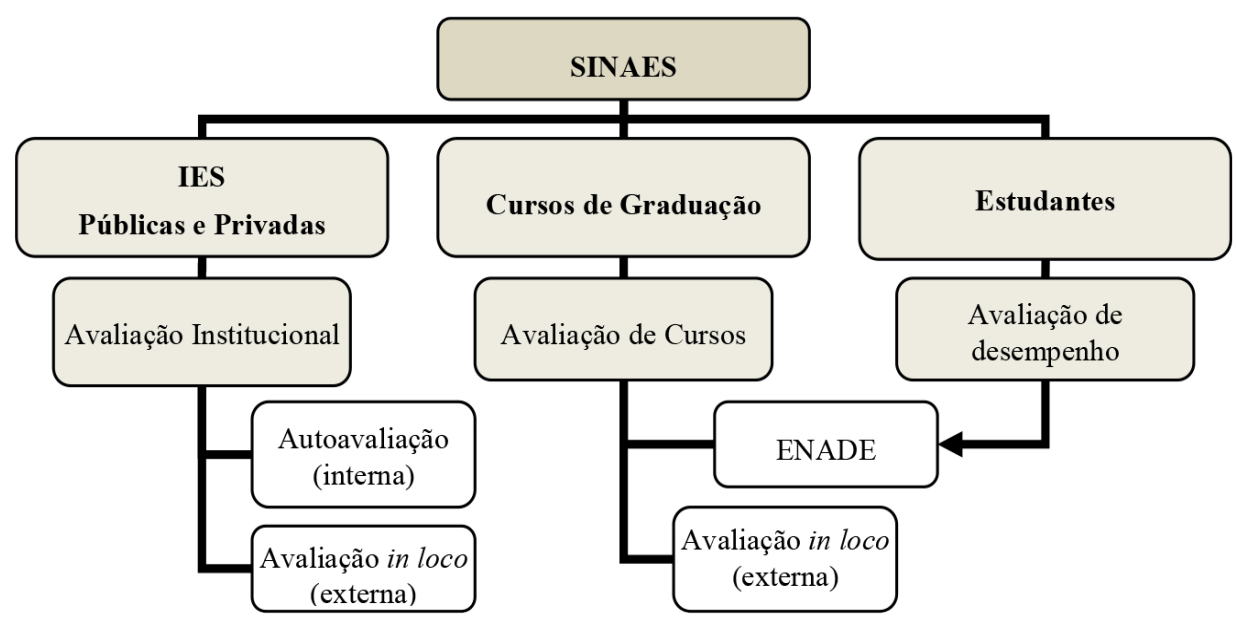

Fonte: Adaptado de INEP (2017).

A organização do sistema possibilita identificar que o fluxo dos processos avaliativos se efetiva, respectivamente, pela sequência: IES, cursos de graduação e desempenho dos estudantes. Ratifica-se este direcionamento por identificar que a avaliação voltada para o credenciamento de uma instituição precede as consequentes autorizações de oferta dos seus cursos de graduação; e que, naturalmente, apenas com a existência dos cursos é possível realizar a avaliação de desempenho dos seus estudantes. 
O termo avaliação, como relatado por Souza e Guerra (2020), relaciona-se à atribuição de julgar utilizando parâmetros e referências de caráter qualitativo e quantitativo. Entende-se que a avaliação ocorre por meio da análise de objetos ou realidades empregando critérios pertinentes e reconhecidos que identifiquem, confirmem ou refutem informações demandadas por determinados grupos de interesses - no caso do SINAES, a avaliação da qualidade das IES, cursos e desempenho dos estudantes perante o Estado e a sociedade.

Para a concretização das análises, são utilizados os instrumentos de avaliação, definidos como as ferramentas que permitem a coleta, organização e contextualização dos dados das IES e cursos de graduação, considerando dimensões e indicadores predefinidos (BRASIL, 2018).

A avaliação, portanto, torna-se o ponto de partida para fundamentar a realização de procedimentos de regulação e supervisão da educação.

\section{RELATÓRIO DE AVALIAÇÃO DO BAP}

O BAP tem como objetivo a formação de profissionais para a Administração Pública, atuando nas esferas municipal, estadual e federal, gerenciando organizações governamentais e organizações não governamentais (ONGs) "[...] de modo proativo, democrático e ético, tendo em vista a transformação e o desenvolvimento da sociedade e do país" (IFPB, 2017a, p. 17).

O processo de reconhecimento do BAP foi realizado entre os dias 24 e 27 de maio de 2017, com a aplicação do instrumento de avaliação de cursos elaborado pelo Instituto Nacional de Estudos e Pesquisas Educacionais Anísio Teixeira (INEP), em 2015, mediante a visita técnica de comissão de avaliadores responsáveis por comprovar a capacidade do bacharelado em obter o seu reconhecimento conforme preconiza o SINAES.

De acordo com o relatório de avaliação externa, produzido pela comissão avaliadora, a análise preliminar do BAP consultou os documentos institucionais, em especial o Plano de Desenvolvimento Institucional (PDI) e o Projeto Pedagógico do Curso (PPC), seguindo de visita às instalações físicas - laboratórios, salas para os docentes, salas de aulas dos polos, espaços administrativos e instalações da biblioteca - e reuniões com a Direção-Geral do IFPB, coordenador do curso, Núcleo Docente Estruturante (NDE), Comissão Própria de Avaliação (CPA), técnicosadministrativos e representantes dos discentes do curso (IFPB, 2017b). 
Os resultados obtidos em cada eixo e indicador de desempenho presente no instrumento de avaliação de cursos concederam ao BAP a definição do Conceito do Curso (CC) 4. Este valor conquistado subsidiou o deferimento do processo de reconhecimento do curso, confirmado por meio da Portaria n. 1.118/ 2017, emitida pelo Ministério da Educação (MEC).

Em destaque, o relatório de avaliação externa in loco para o reconhecimento do BAP obteve como menor valor entre seus indicadores de desempenho e dimensões o conceito 3. Por essa particularidade, consideraremos para a pesquisa esses objetos de análise como aspectos de insuficiência do curso. Essa configuração evidencia a necessidade de ação da gestão do BAP em identificar ações em potencial sobre os temas, objetivando a progressão dos indicadores de conceito 3 para os conceitos 4 ou 5, com a expectativa da melhoria do processo avaliativo.

Torna-se evidente justificar que os indicadores presentes nos instrumentos de avaliação apresentam demandas que tanto remetem à ação direta das estratégias de gestão dos cursos como sinalizam a influência de fatores externos à gestão. Um dos fatores externos considerados ao BAP são as diretrizes previstas em lei, como as determinações oriundas do SINAES, das Diretrizes Curriculares Nacionais (DCNs), da UAB, do PNAP e outros princípios regulatórios. Qualquer atualização dessa base legal traz à tona a necessidade de mudanças compulsórias no curso, demonstrando que a autonomia de gestão está apoiada na observância à legislação pertinente. Outro fator a ser considerado no ambiente externo, para algum dos indicadores de desempenho presentes no relatório, é o contexto educacional: as variáveis da realidade econômica e social da região onde o curso é ofertado e que instituem desafios à sua gestão.

Sob o ponto de vista das insuficiências, em conformidade com os resultados obtidos no último relatório, são analisados os indicadores de desempenho válidos para o BAP e que ainda se aplicam ao novo Instrumento de Avaliação de Cursos de Graduação Presencial e a Distância (IACG), de acordo com os conceitos e ambientes a que se integram.

Sob a ótica da Dimensão 1, Organização Didático-Pedagógica, identifica-se a quase totalidade dos dezessete indicadores de desempenho com conceitos 4 e 5. Os objetos de análise com índices 1.4 e 1.15 - apoio ao discente e ações decorrentes dos processos de avaliação do curso - obtiveram o conceito máximo. Os índices 1.1. 1.2 1.3 , 1.4, 1.5, 1.6, 1.7, 1.8, 1.12, 1.13, 1.16, 1.17, 1.19, 1.20 e 
1.21 foram avaliados com o conceito 4. Apenas o indicador 1.18, que remete ao material didático institucional, obteve o conceito 3 , considerado insuficiente ao curso.

Em destaque, o material didático disponibilizado pelo BAP aos discentes refere-se à bibliografia do PNAP, produzida pelo MEC e acessível apenas de forma digital, atendendo os aspectos presentes no PPC em relação à "acessibilidade, bibliografia adequada às exigências da formação e coerência teórica" (IFPB, 2017b, p. 11). Apesar da indicação sobre o acesso exclusivo do conteúdo de forma digital, o PPC do BAP evidencia a garantia do material didático impresso aos discentes, como um procedimento de apoio psicopedagógico (IFPB, 2017a). Destaca-se, ainda, a ausência de referências ao aspecto da abrangência - presente no indicador de desempenho 1.18.

Em opinião dos discentes, ainda registrada no relatório, identificou-se a falta de aprofundamento dos temas presentes nos materiais didáticos disponibilizados, apesar da indicação de materiais complementares pelos docentes.

Ratifica-se, por meio das características apresentadas no indicador de desempenho 1.18, a falta de controle direto da gestão do BAP sobre a produção dos materiais fornecidos pelo PNAP, mas também a oportunidade, por partir do planejamento docente em cada disciplina ofertada, de decisão e inclusão de materiais adicionais, complementando e aprofundando os conteúdos abordados para os discentes.

Sob o ponto de vista dos conceitos 4 e 5 na Dimensão 1, identifica-se que os aspectos mencionados no PPC do BAP, no PDI da instituição e no relatório de autoavaliação institucional estão presentes e atendem muito bem as políticas institucionais, objetivos, perfil profissional do egresso, estrutura curricular, conteúdos curriculares, metodologia, número de vagas e ações decorrentes dos processos de avaliação. Em especial, as ações acadêmico-administrativas do BAP referentes aos processos da autoavaliação e da avaliação externa foi considerada excelente, demonstrando a presença ativa da CPA e o potencial do curso em se adequar às demandas das diretrizes do SINAES e seus instrumentos avaliativos.

Outros pontos fortes ainda identificados estão relacionados ao processo de ensino e de atividades direcionadas aos discentes, como o estágio curricular supervisionado; atividades complementares; Trabalho de Conclusão de Curso (TCC); apoio ao discente; atividades de tutoria; uso de Tecnologias de Informação 
e Comunicação (TIC) no processo ensino-aprendizagem; mecanismos de interação entre docentes, tutores e estudantes; e os procedimentos de avaliação dos processos de ensino-aprendizagem. Ressalta-se que a avaliação do apoio ao discente foi considerada excelente, ratificada pela existência da Coordenação de Apoio às Pessoas com Necessidades Específicas (COAPNE) na sede do curso, permitindo o atendimento e suporte com profissionais especializados; e pela oferta de aulas de nivelamento em que "[...] são trabalhadas as dificuldades de aprendizado, orientação didático-metodológica, bem como auxílio para a resolução de determinadas dificuldades do dia a dia" (IFPB, 2017b, p. 10).

Na avaliação da dimensão 2, referente ao Corpo Docente e Tutorial, todos os quinze indicadores de desempenho válidos alcançaram resultados associados aos conceitos 4 e 5 . Desses resultados, apenas três indicadores apresentaram conceito 4, representados pelos índices 2.5, 2.9 e 2.14. Os demais objetos de análise avaliados nessa dimensão obtiveram o conceito máximo, sendo respectivamente representados pelos índices 2.1, 2.2 2. 2.3, 2.6, 2.7, 2.8, 2.11, 2.12, 2.13, 2.15, 2.16 e 2.17 .

Com base nas informações presentes no PPC, PDI e fornecidas pela instituição ao e-MEC, identificou-se no relatório de avaliação que as atuações do NDE e do colegiado do curso foram consideradas excelentes.

Do ponto de vista da coordenação do curso, ainda se indicou a atuação com excelência do coordenador do BAP. Outro destaque é o resultado da soma da experiência profissional, de magistério superior e de gestão acadêmica do coordenador, sendo superior a dez anos - valor que permitiu o conceito máximo ao objeto de análise. A carga horária da coordenação, de vinte horas semanais, obteve o conceito 4.

Em relação aos aspectos da tutoria, a titulação e formação dos corpos de tutores do BAP apresentou uma porcentagem de 35,72\% de mestres e a experiência profissional mínima de três anos em cursos EaD superior a 70\%. Ambos indicadores demonstraram uma elevada qualidade das atividades de tutoria no curso.

O corpo docente encontra-se como tópico de maior enfoque dentro da análise definida pelo relatório de avaliação. De todos os indicadores de desempenho referentes à docência, apenas dois foram considerados muito bons: a experiência profissional dos docentes, entre 60\% e $80 \%$, de no mínimo dois 
anos de experiência para bacharelados; e a produção científica, cultural, artística ou tecnológica dos docentes, entre sete e nove produções nos últimos três anos.

Todos os demais indicadores do corpo docente alcançaram a excelência, caracterizados por: titulação com pós-graduação stricto sensu em 86,21\%; regime de trabalho integral na instituição atendido em 100\%; experiência de magistério superior com no mínimo três anos de bacharelado em 93,10\%; oferta de 6,90 vagas do curso por docente; e a relação de 3,77 alunos por docente e tutor do BAP.

Sob a ótica da Dimensão da Infraestrutura, dos dez indicadores considerados válidos, seis foram evidenciados com os conceitos 4 e 5, e quatro com o conceito 3. Dos pontos fortes do curso, o indicador 3.21 - Comitê de Ética em Pesquisa - foi o único objeto de análise a obter o conceito máximo; com os indicadores 3.5, 3.6, 3.7, 3.8 e 3.9 avaliados com o conceito 4. Em relação às insuficiências, os resultados foram representados pelos índices 3.1, 3.2, 3.3 e 3.4, identificados com o conceito 3.

Para o indicador de desempenho 3.1, referente aos gabinetes de trabalho para professores em Tempo Integral (TI), destacou-se no relatório de avaliação que a instituição "[...] dispõe de espaços reservados para alguns professores" (IFPB, 2017b, p. 15). Ficou evidenciada a insuficiência no quantitativo dos espaços, ressaltada pela sinalização da gestão do curso sobre a construção de um novo bloco na instituição, como alternativa viável para implementação de salas para todos os docentes em $\mathrm{TI}$.

No instrumento de avaliação aplicado para este relatório, considerava-se como critérios de análise os aspectos referentes à "disponibilidade de equipamentos de informática em função do número de professores, dimensão, limpeza, iluminação, acústica, ventilação, acessibilidade, conservação e comodidade" (INEP, 2015, p. 28). Pela análise do relatório, não é possível especificar quais aspectos do instrumento apresentam possíveis limitações para a obtenção de conceitos de maior valor.

Ao indicador de desempenho 3.2, em análise ao espaço de trabalho para coordenação do curso e serviços acadêmicos, o relatório demonstrou que o Campus João Pessoa, sede do BAP, oferecia espaço para a coordenação compartilhado com outros cinco cursos pertencentes à Unidade Acadêmica de Gestão e Negócios (UAG) da instituição. O registro do compartilhamento do espaço de coordenação indica um dos potenciais fatores de limitação que não permitiram, na avaliação, a obtenção dos conceitos 4 ou 5. 
O instrumento de avaliação aplicado ao BAP identificava os aspectos da "dimensão, equipamentos, conservação, gabinete individual para coordenador, número de funcionários e atendimento aos alunos e aos professores" (INEP, 2015, p. 28). Dos aspectos avaliados, o relatório evidencia apenas o referente aos equipamentos disponibilizados à coordenação do BAP, entre os quais destacamse: ramal telefônico específico, materiais de escritório, impressora multifuncional e notebook exclusivo.

Em avaliação à sala de professores, presente no índice 3.3, o relatório afirma que a sede no Campus João Pessoa "[...] dispõe de um espaço reservado para os professores com 40m², com uma mesa grande para reunião, boa iluminação, armário para guardar pequenos objetos, banheiro e quatro computadores ligados" (IFPB, 2017b, p. 15).

No instrumento de avaliação aplicado para a avaliação do BAP, foram considerados os aspectos da "[...] disponibilidade de equipamentos de informática em função do número de professores, dimensão, limpeza, iluminação, acústica, ventilação, acessibilidade, conservação e comodidade" (INEP, 2015, p. 29). Identifica-se, em geral, que os aspectos propostos estão inseridos no relatório, mas sem especificações diretas que permitam reconhecer potenciais limitações.

Último indicador considerado como insuficiência à Dimensão 3, o índice 3.4 evidencia a avaliação das salas de aula. O relatório destacou para a sede do BAP, no IFPB Campus João Pessoa, que as salas de aula disponibilizadas possuíam capacidade média para quarenta discentes, contendo equipamentos tecnológicos para auxílio nas atividades de ensino - computador, som e datashow - e atendendo com suficiência os aspectos da "[...] limpeza, iluminação, ventilação, acústica, conservação e comodidade" (IFPB, 2017b, p. 16).

O instrumento de avaliação aplicado ao BAP identificava as " [...] quantidades e número de alunos por turma, disponibilidade de equipamentos, dimensões em função das vagas previstas/autorizadas, limpeza, iluminação, acústica, ventilação, acessibilidade, conservação e comodidade" (INEP, 2015, p. 29). Nota-se que, em geral, os aspectos foram abordados no relatório de avaliação do BAP.

Em relação aos pontos fortes, dentro da Dimensão da Infraestrutura, apenas o objeto de análise sobre a instituição do Comitê de Ética em Pesquisa obteve o conceito máximo. Os indicadores concernentes à disposição de equipamentos de informática aos discentes; bibliografia básica; bibliografia complementar; e sistema 
de controle de produção e distribuição de material didático foram definidos com o conceito 4, de acordo com a demanda já existente.

É importante destacar, diante dos indicadores de desempenho avaliados como insuficiências na dimensão da Infraestrutura - e em especial às salas de aula -, que o BAP, como curso de modalidade EaD, segmenta-se entre sua sede e polos.

Na sede, situada no IFPB Campus João Pessoa, é que estão localizados os espaços relativos aos gabinetes de trabalho para professores em $\mathrm{TI}$, coordenação do curso e sala de professores. As salas de aula, como os espaços utilizados para atividades presenciais do BAP, localizam-se tanto na sede como nos polos UAB, integrados aos municípios onde são ofertadas as vagas do curso: Alagoa Grande, Araruna, Mari e Lucena - todos presentes no Estado da Paraíba.

De acordo com o Decreto n. 9.057/2017, legislação referente à regulamentação da EaD no país, os processos de regulação e supervisão de IES e cursos de graduação são submetidos à avaliação externa in loco na sede da instituição. Portanto a visita da comissão técnica é exclusiva à sede do curso. Apesar de destaque no relatório de avaliação para o reconhecimento do BAP, em tópico referente à síntese da ação preliminar, com "[...] visitas aos laboratórios, salas docentes, salas de aulas do polo" (IFPB, 2017b, p. 3, grifo nosso), a análise do indicador 3.4 é voltada em específico à estrutura física das salas de aula do IFPB Campus João Pessoa.

De acordo com o contexto, os indicadores apresentados como insuficiências à dimensão 3 apresentam características que remetem à influência direta da gestão do BAP, devido à manutenção dos espaços acadêmicos e pedagógicos estar amparada sob a responsabilidade dos gestores, em sua sede; e de fatores externos, por integrar ao planejamento do curso o desafio em pleitear e buscar soluções sobre esses aspectos junto à UAG e à Direção-Geral do campus ao qual está integrado.

\section{NOVOS INDICADORES E CRITÉRIOS DE ANÁLISE PARA A AVALIAÇÃO DO BAP}

As mudanças propostas em 15 de dezembro de 2017, pela Nota Técnica n. 16, elaborada pela INEP, reformularam os instrumentos de avaliação de cursos. Entre as alterações realizadas no IACG orientado para o reconhecimento e a renovação de reconhecimento, estão a inclusão de novos indicadores de desempenho e a renovação dos critérios de análise dos indicadores já existentes. 
Para a pesquisa, são identificados quatro novos indicadores no instrumento, com aplicações comprovadas ao BAP: conhecimentos, habilidades e atitudes necessárias às atividades de tutoria; Ambiente Virtual de Aprendizagem (AVA); equipe multidisciplinar; e experiência no exercício da docência na EaD.

Integrado à Dimensão da Organização Didático-Pedagógica, o primeiro indicador de desempenho identificado no IACG, citado no índice 1.15, refere-se aos conhecimentos, habilidades e atitudes necessárias às atividades de tutoria. $\mathrm{O}$ objeto de análise, compulsório aos cursos de EaD, amplia a avaliação dos aspectos sobre o tema - também presente no indicador 1.14, referente ao atendimento das demandas por atividades de tutoria no curso.

O indicador 1.15 considera, em seus critérios de análise, para a obtenção do conceito 3, que "[...] os conhecimentos, habilidades e atitudes da equipe de tutoria são adequados para a realização de suas atividades e suas ações estão alinhadas ao PPC, às demandas comunicacionais e às tecnologias adotadas no curso" (INEP, 2017b, p. 16, grifo nosso). Como critérios adicionais para obtenção dos conceitos 4 e 5, respectivamente, considera-se que no objeto de análise "[...] são realizadas avaliações periódicas para identificar necessidade de capacitação dos tutores e há apoio institucional para adoção de práticas criativas e inovadoras para a permanência e êxito dos discentes" (INEP, 2017, p. 16, grifo nosso).

Sob a perspectiva dos critérios apresentados, foi possível identificar no último relatório de avaliação externa in loco do BAP que o IFPB Campus João Pessoa, sede do curso, promove treinamentos "[...] a fim de conscientizar os tutores da importância de seu papel como mediador" (IFPB, 2017b, p. 10). Essa característica demonstra o potencial do curso em atender ao critério aditivo definido no conceito 4 do indicador 1.15 .

Ainda sob a ótica da Dimensão da Organização Didático-Pedagógica, destacase a inclusão do indicador de desempenho referente ao AVA, presente no índice 1.17. Assim como o indicador 1.15, o objeto de análise atende à avaliação das novas demandas para os cursos EaD - em parte pela publicação da Portaria MEC n. 1.134/2016, que regularizava a oferta de disciplinas na modalidade a distância, em ano anterior à instituição do novo IACG. O AVA, para obtenção do conceito 3, " [...] apresenta materiais, recursos e tecnologias apropriadas, que permitem desenvolver a cooperação entre tutores, discentes e docentes, a reflexão sobre 
o conteúdo das disciplinas e a acessibilidade metodológica, instrumental e comunicacional" (INEP, 2017, p. 17, grifo nosso).

Em referência aos critérios adicionais que atendem aos conceitos $4 \mathrm{e}$ 5, analisa-se que o AVA “[...] passa por avaliações periódicas devidamente documentadas, que resultam em ações de melhoria contínua" (INEP, 2017, p. 17, grifo nosso).

No IFPB, a plataforma utilizada para os cursos EaD como AVA é o Moodle. De acordo com o PPC do BAP, o Moodle é responsável pela interação e pelo compartilhamento de informações entre discentes, docentes e tutores, permitindo a utilização de distintos recursos didáticos, como "[...] arquivos de apostila, casos de ensino, artigos científicos, slides de apresentação dos conteúdos, planilhas eletrônicas, filmes" (IFPB, 2017b, p. 167).

Em investigação ao último relatório de avaliação do BAP, no indicador de desempenho referente aos mecanismos de interação entre docentes, tutores e estudantes, avaliou-se que o Moodle permitiu aos discentes o acesso a todo conteúdo disponibilizado no curso e ao desenvolvimento das atividades propostas; além de que, a utilização de ferramentas como chat e fóruns na plataforma ajudou a ampliar a interação entre os discentes e tutores (IFPB, 2017b). Esses aspectos destacam-se como potenciais requisitos para atender ao conceito 3 do indicador de desempenho 1.17, durante a aplicação do IACG.

Associado à Dimensão do Corpo Docente e Tutorial, um novo indicador de desempenho incluído refere-se à equipe multidisciplinar, atribuído ao índice 2.2. Também direcionado aos cursos na modalidade EaD, o indicador retrata, como critérios de análise para o conceito 3, que a equipe "[...] estabelecida em consonância com o PPC, é constituída por profissionais de diferentes áreas do conhecimento e é responsável pela concepção, produção e disseminação de tecnologias, metodologias e os recursos educacionais para a educação a distância" (INEP, 2017, p. 22, grifo nosso).

O BAP, como consta em seu PPC, apresenta, além do corpo docente e tutorial, uma equipe de apoio administrativo integrada por dois servidores efetivos definidos pela UAB - que têm o cargo de técnico em assuntos educacionais -, que "[...] também operacionalizam as avaliações internas do curso para melhoria contínua de todos os seus segmentos" (IFPB, 2017b, p. 188). Destaca-se, ainda, no relatório, o suporte de equipes de logística e de apoio tecnológico presentes 
no IFPB Campus João Pessoa, sede do curso. A diversidade identificada na equipe multidisciplinar, por meio de consulta ao PPC, apresenta um potencial do BAP em atender ao conceito 3 do indicador de desempenho 2.2 às próximas avaliações externas in loco ao curso.

Finalizando a análise dos novos indicadores, ainda sob a ótica da segunda dimensão, ocorreu a inclusão do indicador de desempenho referente à experiência do corpo docente no exercício da docência na EaD, atribuído ao índice 2.10.

Como critérios adicionais para obtenção dos conceitos 4 e 5, o IACG destaca que, além dos aspectos anteriores, a experiência do corpo docente na área de EaD deve permitir a elaboração de "[...] avaliações diagnósticas, formativas e somativas, utilizando os resultados para redefinição de sua prática docente no período, exerce liderança e é reconhecido pela sua produção" (INEP, 2017, p. 26, grifo nosso). Não foram identificados registros que remetam ao atendimento dos critérios demandados pelo indicador 2.10 no PPC ou no relatório de avaliação do BAP.

É importante destacar que, além da inclusão dos novos indicadores de desempenho citados, a serem aplicados aos futuros procedimentos avaliativos no BAP, ocorreram ainda alterações significativas na redação dos critérios de análise dos indicadores que permaneceram do instrumento de avaliação de cursos anteriores para o novo IACG. A investigação pormenorizada dos distintos aspectos presentes em cada um dos indicadores, por sua complexidade, tornaria a análise excessivamente densa e extensa. Para objetividade da pesquisa, serão evidenciadas as mudanças dos critérios integrados aos pontos de insuficiência identificados no BAP.

Entre os indicadores de desempenho considerados como insuficientes, está o material didático, apresentado no índice 1.18 do atual IACG e integrado à Dimensão da Organização Didático-Pedagógica.

Identifica-se no indicador 1.18, como uma das alterações dos critérios de análise do instrumento anterior para o atual, a inserção dos termos metodológico e instrumental à acessibilidade. A especificação da acessibilidade ratifica sua aplicação ao ensino e à aprendizagem (INEP, 2013), atributo inerente ao material didático ofertado pelo BAP.

Acerca dos critérios aditivos para a obtenção dos conceitos 4 e 5, ao indicador 1.18 são acrescentadas características sobre a linguagem inclusiva 
e acessível, além do uso de recursos inovadores (INEP, 2017). Os aspectos da inclusão e acessibilidade, evidenciados por meio da linguagem dos materiais didáticos, oportunizam a democratização do acesso e permanência dos discentes, considerando "[...] não só a existência de deficiências, mas também das diferenças de classe social, gênero, idade e origem étnica" (INEP, 2019, p. 54).

Em especial, destaca-se a presença contínua do aspecto da inovação nos critérios aditivos, como identificado no indicador de desempenho 1.18. A inovação tornou-se um dos principais atributos de qualidade em referência aos critérios aditivos dos indicadores do IACG, em específico para obtenção do conceito máximo da avaliação. Como exemplo, entre os dezoitos indicadores de desempenho integrados à Dimensão da Organização Didático-Pedagógica - e considerados para as futuras avaliações do BAP -, nove deles identificam ações ou práticas inovadoras como critérios que atendem a obtenção do conceito 5.

Por definição, as práticas inovadoras remetem a ações consideradas como "[...] raras na região, no contexto educacional ou no âmbito do curso" (INEP, 2019, p. 59), induzindo a utilização de recursos criativos e transformadores que atendam às demandas institucionais ou do curso.

Em continuação à investigação dos critérios de análise dos indicadores de desempenho classificados como insuficientes ao BAP, encontra-se o indicador referente à avaliação do espaço de trabalho para docentes em $\mathrm{TI}$.

Integrado à Dimensão da Infraestrutura e estabelecido no índice 3.1 do IACG, os novos critérios de análise, considerados para o cumprimento de conceito 3, destacam que esses espaços para os docentes em TI "[...] viabilizam ações acadêmicas, como planejamento didático-pedagógico, atendem às necessidades institucionais e possuem recursos de tecnologias da informação e comunicação apropriados" (INEP, 2017, p. 30, grifo nosso). Observa-se a alteração no foco da avaliação de características estritamente estruturais, presentes no antigo instrumento - como acústica, ventilação, iluminação e dimensão - para a verificação do atendimento das funções às quais o espaço é designado.

Em referência aos critérios aditivos para os conceitos 4 e 5, respectivamente, o indicador de desempenho 3.1 refere-se que estes espaços "[...] garantem privacidade para uso dos recursos, para o atendimento a discentes e orientandos, e para a guarda de material e equipamentos pessoais, com segurança" (INEP, 2017, p. 30, grifo nosso). 
O próximo indicador de desempenho avaliado como insuficiente é atribuído ao espaço de trabalho para o coordenador, presente no índice 3.2. Assim como o indicador anterior, ocorrem mudanças nos critérios de análise com foco na confirmação das funções atribuídas ao espaço, indicando que este "[...] viabiliza as ações acadêmico-administrativas, possui equipamentos adequados e atende às necessidades institucionais" (INEP, 2017, p. 30, grifo nosso).

Além dos aspectos apresentados para a obtenção do conceito 3, o indicador evidencia como critérios aditivos que o espaço de trabalho do coordenador "[...] permite $\mathrm{o}$ atendimento de indivíduos ou grupos com privacidade e dispõe de infraestrutura tecnológica diferenciada, que possibilita formas distintas de trabalho" (INEP, 2017, p. 30, grifo nosso).

Ainda sob a Dimensão da Infraestrutura, outro ponto de insuficiência identificado no BAP refere-se ao indicador de desempenho do espaço de trabalho para os docentes, denominado no IACG como sala coletiva de professores e identificado por meio do índice 3.3.

Os critérios de análise para a conceituação de valor 3 do indicador afirmam que "A sala coletiva de professores viabiliza o trabalho docente, apresenta acessibilidade e possui recursos de tecnologias da informação e comunicação apropriados para o quantitativo de docentes" (INEP, 2017, p. 31, grifo nosso). Assim como os indicadores de desempenho referidos anteriormente, integrados à Dimensão da Infraestrutura, nota-se a adaptação de aspectos descritivos do instrumento anterior para uma avaliação sobre a suficiência do espaço de acordo com sua função. Destaca-se a permanência, do instrumento de avaliação anterior para o IACG, da análise quantitativa sobre a relação do número de recursos de TIC por docentes.

Para a obtenção dos conceitos 4 e 5, no indicador 3.3, são adicionados os critérios aditivos que avaliam se a sala coletiva de professores "[...] permite o descanso e atividades de lazer e integração e dispõe de apoio técnicoadministrativo próprio e espaço para a guarda de equipamentos e materiais" (INEP, 2017, p. 31, grifo nosso).

E, como último indicador de desempenho avaliado como insuficiente ao BAP, estão as salas de aula, no índice 3.4 do IACG. O instrumento destaca como critérios de análise, para obter o conceito 3, que as salas de aula "[...] atendem às necessidades institucionais e do curso, apresentando manutenção periódica, 
conforto e disponibilidade de recursos de tecnologias da informação e comunicação adequados às atividades a serem desenvolvidas" (INEP, 2017, p. 31, grifo nosso).

As especificidades sobre a quantidade de alunos por turma, presentes no instrumento anterior, são substituídas pela avaliação do atendimento às demandas do BAP e sua sede. Outro destaque é na informação acrescentada aos critérios sobre os equipamentos disponibilizados nos espaços, referindo-os às TIC.

Aos critérios aditivos do indicador de desempenho 3.4, em referência aos conceitos 4 e 5 do IACG, é evidenciado que as salas de aula permitam "[...] flexibilidade relacionada às configurações espaciais, oportunizando distintas situações de ensino-aprendizagem, e possuem outros recursos cuja utilização é comprovadamente exitosa" (INEP, 2017, p. 31, grifo nosso).

\section{CONSIDERAÇÕES FINAIS}

A avaliação da qualidade na Educação Superior se inseriu definitivamente no panorama histórico das políticas públicas educacionais, em especial com a vigência do SINAES - no ano de 2004. O sistema objetiva assegurar o processo nacional de avaliação e regulação das IES, dos cursos de graduação e do desempenho dos estudantes, com o objetivo de melhorar a qualidade da educação e orientar a expansão da sua oferta. Como processo contínuo, a avaliação tornou-se um aspecto integrado à gestão e ao planejamento de instituições e cursos, determinando parte de suas ações para atender às especificações de procedimentos e instrumentos avaliativos.

Os desafios inerentes ao BAP como curso EaD, pertencente a uma instituição que se adequa às novas atribuições integradas às IES, a partir de 2008, destacam a necessidade de identificar como os referenciais teóricos e metodológicos preconizados pelo SINAES podem contribuir para a melhoria dos processos avaliativos realizados.

Foram identificados e analisados cinco indicadores com conceito 3, o menor valor obtido no último relatório de avaliação externa in loco do curso, caracterizados como insuficientes: material didático institucional; gabinetes de trabalho para professores em Tl; espaço de trabalho para coordenação do curso e serviços acadêmicos; sala de professores; e salas de aula.

Destacaram-se, ainda em análise, quatro novos indicadores incluídos no IACG, com aplicações comprovadas ao BAP: conhecimentos, habilidades e atitudes 
necessárias às atividades de tutoria; AVA; equipe multidisciplinar; e experiência no exercício da docência na EaD.

Sob a ótica das alterações dos critérios de análise e critérios aditivos instituídas no IACG, por meio da Nota Técnica n. 16/2017, do INEP, evidenciam-se os aspectos de insuficiência e os novos indicadores relacionados ao BAP - conhecimento complementar que auxilie os gestores nas tomadas de decisões diante das novas demandas do IACG, objetivando a melhoria da qualidade do processo avaliativo às futuras avaliações para a renovação de reconhecimento do curso.

\section{REFERÊNCIAS}

BRASIL. Ministério da Educação. Portaria Normativa n. 840, de 24 de agosto de 2018. Dispõe sobre os procedimentos de competência do Instituto Nacional de Estudos e Pesquisas Educacionais Anísio Teixeira referentes à avaliação de instituições de educação superior, de cursos de graduação e de desempenho acadêmico de estudantes. Diário Oficial da União, n. 169, de 31 agosto de 2018.Brasília-DF: MEC, 2018. Disponível em: http://download.inep.gov.br/educacao_superior/avaliacao_institucional/legislacao_ normas/2018/portaria_normativa_n840_de_24082018_republicada_31082018.pdf. Acesso em: 14 fev. 2020.

BRASIL. Lei n. 10.861, de 14 de abril de 2004. Institui o Sistema Nacional de Avaliação da Educação Superior - SINAES e dá outras providências. Brasília-DF, 2004. Disponível em: http://www.planalto.gov.br/ccivil_03/_ato2004-2006/2004/lei//10.861.htm. Acesso em: 10 set. 2020.

CAVALCANTI, Lourdes Maria Rodrigues; GUERRA, Maria das Graças Gonçalves Vieira. Diagnóstico Institucional da Universidade Federal da Paraíba a partir da Análise SWOT. Revista Meta: Avaliação Rio de Janeiro, v. 11, n. 33, p. 694-718, set./dez. 2019. DOI http:// dx.doi.org/10.22347/2175-2753v11i33.2270

INSTITUTO FEDERAL DE EDUCAÇÃO, CIÊNCIA E TECNOLOGIA DA PARAÍBA [IFPB]. Plano Pedagógico de Curso - bacharelado em Administração Pública. [Versão atualizada de fevereiro de 2017]. João Pessoa: IFPB, 2017a. Disponível em: https://estudante.ifpb.edu. br/media/cursos/146/documentos/PPC_BAP_BM3Z2Qv.pdf. Acesso em: 10 maio 2020.

INSTITUTO FEDERAL DE EDUCAÇÃO, CIÊNCIA E TECNOLOGIA DA PARAÍBA [IFPB] Relatório de avaliação externa do Reconhecimento de Curso - bacharelado em Administração Pública. Publicado em 29 de maio de 2017. João Pessoa: IFPB, 2017b. Disponível em: https://www.ifpb.edu.br/cpa/documentos/relatorios-de-avaliacao-externa/relatorio2017-campus-joao-pessoa-administracao-publica.pdf. Acesso em: 11 maio 2020. 
INSTITUTO NACIONAL DE ESTUDOS E PESQUISAS EDUCACIONAIS ANÍSIO TEIXEIRA [INEP]. Avaliação in loco: Glossário dos Instrumentos de Avaliação Externa. 4. ed. [Atualizado em 2 de setembro de 2019]. Brasília, DF: INEP, 2019. Disponível em: http://download.inep. gov.br/educacao_superior/avaliacao_institucional/apresentacao/glossario_4_edicao.pdf. Acesso em: 3 mar. 2020.

INSTITUTO NACIONAL DE ESTUDOS E PESQUISAS EDUCACIONAIS ANÍSIO TEIXEIRA [INEP]. Nota Técnica n. 16/2017/CGACGIES/DAES. Dispõe sobre os novos instrumentos de avaliação externa: Instrumento de Avaliação Institucional Externa - Presencial e a Distância (IAIE); Instrumento de Avaliação de Cursos de Graduação - Presencial e a Distância (IACG). Publicada em 15 de dezembro de 2017. Brasília, DF: CGACGIES/DAES, 2017. Disponível em: https://abmes.org.br/arquivos/legislacoes/Nota-Tecnica-CGACGIES-DAES-016-2017. pdf. Acesso em: 11 mar. 2020.

INSTITUTO NACIONAL DE ESTUDOS E PESQUISAS EDUCACIONAIS ANÍSIO TEIXEIRA [INEP]. Instrumento de Avaliação de Cursos de Graduação - presencial e a distância. Subsidia os atos autorizativos de cursos - autorização, reconhecimento e renovação de reconhecimento nos graus de tecnólogo, de licenciatura e de bacharelado para a modalidade presencial e a distância. Brasília, DF: INEP, 2015. Disponível em: http://download.inep.gov.br/ educacao_superior/avaliacao_cursos_graduacao/instrumentos/2015/instrumento_ cursos_graduacao_publicacao_agosto_2015.pdf. Acesso em: 3 maio 2020.

INSTITUTO NACIONAL DE ESTUDOS E PESQUISAS EDUCACIONAIS ANÍSIO TEIXEIRA [INEP]. Documento orientador das Comissões de Avaliação in loco para Instituições de Educação Superior com enfoque em acessibilidade. Brasília, DF: INEP, 2013. Disponível em: http://download.inep.gov.br/educacao_superior/avaliacao_institucional/documentos_ orientadores/2016/documento_orientador_em_acessibilidade_avaliacao_institucional. pdf. Acesso em: 24 ago. 2020.

SOUZA, Saulo Rodrigo Alves de; GUERRA, Maria das Graças Gonçalves Vieira. Autoavaliação institucional da Universidade Federal da Paraíba: diagnóstico a partir da Comissão Própria de Avaliação. Revista Diálogo Educacional, v. 20, n. 64, mar. 2020. Disponível em: https:// periodicos.pucpr.br/index.php/dialogoeducacional/article/view/26133/24105. Acesso em: 11 maio 2020.

\section{Sobre os autores:}

Marcos Vasconcelos Paiva: Mestre em Políticas Públicas, Gestão e Avaliação do Ensino Superior pela Universidade Federal da Paraíba (UFPB). Especialista em Turismo de Base Local e bacharel em Turismo com habilitação em Marketing Turístico pela UFPB. Técnico-administrativo do Instituto Federal da Paraíba 
(IFPB) - Campus João Pessoa. E-mail: marcosvpaiva@hotmail.com, Orcid: http://orcid.org/0000-0003-2361-5967

Maria das Graças Gonçalves Vieira Guerra: Pós-doutora pela Universidade do Porto (2019), Portugal. Doutorado em Educação pela Universidade Federal da Paraíba (UFPB). Mestre em Administração pela UFPB. Especialista em EaD pelo Centro Universitário da Grande Dourados (UNIGRAN-EaD). Bacharela em Ciências Contábeis pela UFPB e licenciada em Pedagogia pela UNIGRAN-EaD. Professora associada III do Centro de Educação da UFPB, professora dos quadros permanentes dos Programas de Pós-Graduação em Educação, e de Políticas Públicas, Gestão e Avaliação da Educação Superior da UFPB. E-mail: gracinhavieira@yahoo.com.br, Orcid: http://orcid.org/0000-0002-6943-0338

Recebido em: 28/09/2020

Aprovado em: 09/05/2021 
